\title{
Em busca de uma fronteira mais porosa e aberta à interlocução
}

Belisa Figueiró $^{1}$

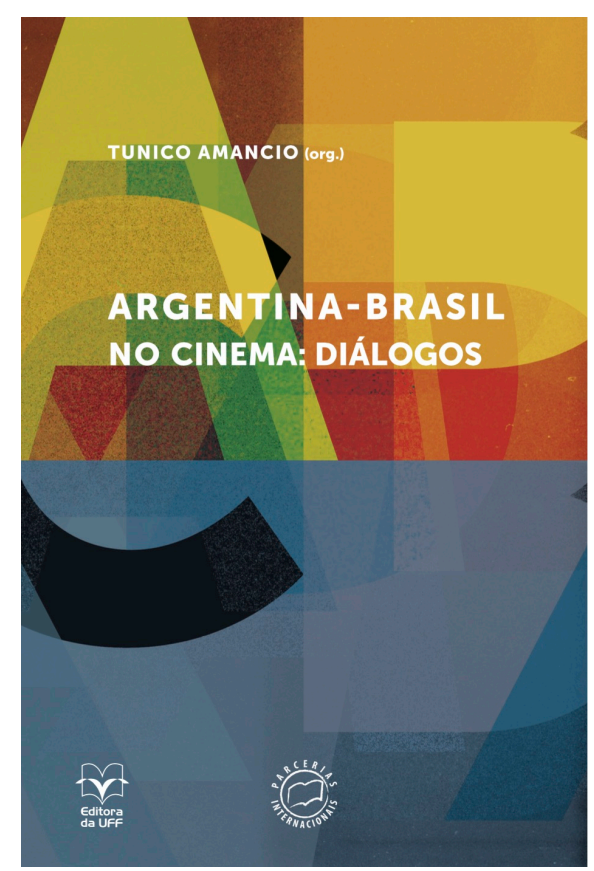

\section{Resenha}

AMANCIO, Tunico (Org.). Argentina-Brasil no cinema: diálogos. Niterói: Editora da UFF, 2014. 256 p.

' Mestranda do Programa de Pós-Graduação em Imagem e Som (PPGIS) da Universidade Federal de São Carlos (UFSCar). É graduada em Comunicação Social/Jornalismo. Foi produtora de informação e imagem do Programa Cinema do Brasil/Apex-Brasil, editora-assistente da Revista de Cinema e do Centro de Análise do Cinema e do Audiovisual; e produtora editorial da coleção de livros "Indústria 
A construção da produção cinematográfica do Brasil não foi completamente alheia à da Argentina, embora tenha registrado alguns momentos mais próximos e fluidos do que outros. E mesmo naqueles mais distantes, é possível traçar um paralelo que evidencie ao menos alguns elementos políticos e econômicos que marcaram um ambiente mais obscuro ou mais solar para os dois países. Nesta busca por uma aproximação histórica, esta obra organizada pelo pesquisador e professor Tunico Amancio apresenta 14 estudos comparados com casos bastante específicos, mas que retratam esse diálogo desde o cinema mudo até os dias de hoje.

Composto por artigos de pesquisadores brasileiros e argentinos - escritos em seus idiomas nativos -, Argentina-Brasil no cinema: diálogos fecha a trilogia iniciada com Brasil-México: aproximações cinematográficas (2011) e Corpos em projeção: gênero e sexualidade no cinema latino-americano (2013), produzida por estudiosos da PRALA - Plataforma de reflexão sobre o audiovisual latinoamericano, ligados ao Programa de Pós-Graduação em Comunicação da Universidade Federal Fluminense (UFF).

Além de ser uma fonte preciosa de pesquisas focadas nas duas maiores cinematografias sul-americanas, o conjunto dos textos engloba as mais diferentes perspectivas, sem deixar de convergir para um propósito em comum muito bem delineado. Desde a construção de um cinema nacional e da memória dos anos 1960 e 1970, passando pelas produções experimentais até chegar às cooperações oficiais que tanto beneficiam a produção e a circulação dos nossos filmes nessa fronteira que ainda é insuficientemente porosa.

Para começar, em "Imagens para dois jovens gigantes em busca de lugar no concerto das nações", Fabián Núñez analisa as primeiras duas décadas das cinematografias brasileira e argentina, propondo um estudo sobre a ideia de "cinema nacional" dos anos 1890 a 1910. A partir do final dos anos 1900, com o "aburguesamento" do cinema, as salas de exibição se convertem "em um espaço de rito social" que começa a ser frequentado pela "boa sociedade". O cinema ficcional, aponta Núñez, surgiu em ambos os países no mesmo período, por volta de 1908, pelas mãos de Mario Gallo, na Argentina, e Júlio Ferrez, no Brasil - com foco especial nas figuras do gaucho e do caipira, respectivamente. E vai dar 
origem ao discurso do cinema nacional e em nome de uma indústria cinematográfica na década de 1920.

Em "Cinemas nacionais e latino-americanos imaginados pela crítica argentina contemporânea", Eliska Altmann investiga a recepção dos filmes e a busca da identidade pela revista El Amante e pelo jornal Página 12. A partir desses textos, trabalha as interligações dentro da Argentina, inclusive quando propõe uma aproximação entre os filmes de Lisandro Alonso, Lucrecia Martel e Pablo Trapero, que criariam uma certa unidade dentro da sua própria diversidade. Importante também acompanhar a análise da crítica sobre os filmes de Glauber Rocha, que seriam "muito mais latino-americanos" por falarem de lugares particulares do que as produções pretensamente transversais sobre a América Latina, como Diários de motocicleta, de Walter Salles.

Alcilene Cavalcante, em "A representação do passado nas telas: os discursos históricos em filmes de Bemberg e Yamasaki", relaciona os filmes Camila e Parayba, mulher macho dentro dos processos de transição democrática da Argentina e do Brasil, fazendo um apanhado histórico dos filmes e mostrando como os personagens transitam pela truculência do período para indicar aproximações e distanciamentos para diálogos em comum, embora de lados opostos da fronteira.

Tunico Amancio, além de organizar a obra, também é o autor do artigo "Argentina-Brasil: o sobrenatural no cinema dos anos 1970 (Favio e Miguel Borges em diálogo)". No texto, ele esmiúça a marca pessoal "muito definida" ao longo da carreira dos dois diretores e o contexto histórico da época, com especial atenção em Nazareno Cruz y el Lobo e Pecado na sacristia, filmes do período que recuperaram o imaginário popular do público em cada país de origem.

A obra de Leonardo Favio também é objeto de análise do artigo de Gonzalo Aguilar, que traça um paralelo com Glauber Rocha e a crise da racionalidade. Para isso, o autor parte de Juan Moreira e Antonio das Mortes ( $O$ dragão da maldade contra o santo guerreiro), e trabalha com a premissa de que a poética cinematográfica da coreografia e do povo, tão evidentes em Glauber, conflui muito mais com o cinema de Favio do que com o de Fernando Solanas, nesta comparação, sob a égide dos movimentos revolucionários da época. 
"Em nome do pai: intimidade e memória em Person e Ernesto Sabato, Mi Padre", o ensaio de Denise Tavares aponta como Marina Person e Mario Sabato, os filhos que se tornaram cineastas, revisitaram as memórias (suas ou de pessoas próximas, ou ainda em depoimentos dos próprios personagens) para recriar a imagem de seus pais em documentários biográficos, mas que também acabaram por revelar o período pós-sombrio do Brasil e da Argentina, por meio de um retrato íntimo.

Silvia Oroz, uma das pesquisadoras argentinas mais renomadas e com larga produção historiográfica, também é autora de um dos artigos do livro. Em "La 'culpabilidad' debelada. El guerrillero de 1970 en el cine los 1990", ela mostra como finalmente os protagonistas da luta armada são retratados em primeiro plano pelos filmes brasileiros e argentinos, com especial atenção em Lamarca e Golpes a mi puerta, ambos de 1994.

"Vanguardas à margem" é o ensaio de Daniel Caetano sobre como o Cinema Marginal surgiu após o Cinema Novo, assim como o Grupo dos Cinco apareceu depois da Geração dos 60, na Argentina, propondo semelhanças e diferenças entre as relações dos cineastas. Ao contrário dos brasileiros, Caetano lembra que os argentinos se uniram em torno de uma visão mais empresarial e inclusive criaram um estúdio próprio. Já os colegas do lado de cá estavam mais unidos "por uma questão de idade, geracional, não por escolha própria". Julio Bressane, Ozualdo Candeias e André Luiz Oliveira sequer conviveram, aponta o autor.

Estevão Garcia se debruça, inicialmente, em um panorama histórico comparativo do cinema entre as décadas de 1960 e 1970 em "Belair e CAM: os surtos experimentais clandestinos nos cinemas brasileiro e argentino" para, em seguida, analisar as duas produtoras. Tanto Belair quanto CAM (Cine Argentino Moderno) tiveram vida efêmera e, para o autor, se aproximavam pelo "conceito de antiarte", faziam o contato com o espectador "pela via da agressão" e recusavam o "cinema como mercadoria". Como exemplos de filmes pouco tradicionais, Garcia destrincha Sem essa aranha e Puntos suspensivos.

"Tango e samba na tela - Paralelismos" é o artigo de Carlos Eduardo Pereira e Arnaldo Di Pace, que mostra como os dois ritmos foram projetados como símbolos dos traços culturais da Argentina e do Brasil em todo o mundo, fundamentais na 
passagem do cinema mudo para o sonoro, e até hoje estão presentes nas duas cinematografias. Desde a marginalidade nos primórdios das exibições elitistas, passando pelo protagonismo de Carlos Gardel nas versões regionais de filmes norte-americanos, até chegar ao tango como tema principal em filmes de Fernando Solanas e Carlos Saura, por exemplo. Do lado brasileiro, os autores lembram os musicais carnavalescos, a exportação do samba, inclusive em filmes de Walt Disney, até chegar aos documentários e cinebiografias dos anos 2000.

Fernando Morais da Costa explora o som em filmes contemporâneos. Em seu recorte, estão Infância clandestina e o som que situa o espectador no tempo e no espaço da época da ditatura militar a partir dos conceitos de Michel Chion; O olhar invisível e o nacionalismo do hino argentino que ecoa na disciplina; O homem ao lado, que explora os sons fora de quadro e também como fronteira entre os espaços público e privado; $O$ som ao redor e os ruídos que emolduram o cotidiano das pessoas de classes sociais diferentes; Na estrada e o som como voz narrativa; e Transeunte, com sons hiper-realistas e por vezes sobrepostos.

Em "Fotografia do homem, fotografia da mulher: uma análise dos filmes Elvis \& Madona e Plan B", Marina Cavalcanti Tedesco examina as fronteiras de gênero e sexualidade por meio da iluminação, que pode reforçar ou amenizar as características masculinas e femininas dos personagens, como a luz direta, ou contraluz, e o posicionamento dos refletores para provocar penumbras, podendo ainda atenuar ou enfatizar linhas de expressão ou marcas nos rostos. "A quem caberiam as sombras mais densas?", questiona a autora.

Com uma análise mais mercadológica, Marina Moguillansky e Hadija Chalupe da Silva encerram a obra problematizando as coproduções internacionais entre Argentina e Brasil. Moguillansky aponta para a importância dos fundos disponíveis (como o Programa Ibermedia e o Edital de Cooperação entre ANCINE e INCAA) para além da mera assinatura dos acordos de coprodução bilaterais e multilaterais. Ela faz também um levantamento dos filmes realizados em conjunto entre os anos de 1997 a 2012, com ênfase na Argentina como parceira majoritária. Silva, por sua vez, contextualiza o ambiente normativo e narra o desenvolvimento dos acordos, convênios e das coproduções iniciais até os dias de hoje, e evidencia a importância de vislumbrar as parcerias como possibilidade não só de complemento 
do orçamento, mas também de abertura de novos mercados para a recuperação do valor investido. 